\title{
Methods in reducing surface reflected glint for shipborne above-water remote sensing
}

\author{
S. P. Garaba \\ shungu.garaba@uni-oldenburg.de
}

\section{O. Zielinski}

\begin{abstract}
Institute for Chemistry and Biology of the Marine Environment - Terramare, Carl von Ossietzky University of Oldenburg, Schleusenstraße 1, 26382 Wilhelmshaven, Germany

Institute for Chemistry and Biology of the Marine Environment - Terramare, Carl von Ossietzky University of Oldenburg, Schleusenstraße 1, 26382 Wilhelmshaven, Germany
\end{abstract}

Surface reflected glint is a curse for ocean color remote sensing from above-water platforms. In calibrated above-water shipborne radiometry, there are several surface reflected glint correction approaches widely implemented. These approaches were developed using radiative transfer simulations and/or field measurements in different water types, sea states, and cloud conditions. To date no particular surface reflected glint correction approach has been prescribed in ocean optics standard protocols. Without synoptic inherent optical properties to accurately determine apparent optical properties, glint correction is therefore rather qualitative or subjective. There is need to fully take inventory of uncertainties resulting from such differences. We look at different methods that have been implemented in calibrated shipborne radiometry and how surface reflected glint is corrected for using these available approaches. Field measurements are utilized to assess how the correction approaches perform under clear and overcast skies, we also elucidate on aspects for further improvements.

[DOI: http://dx.doi.org/10.2971/jeos.2013.13058]

Keywords: Surface reflected glint, sunglint, skyglint, shipborne remote sensing, ocean color

\section{INTRODUCTION}

Nowadays operational oceanographic observatories are becoming more prominent at the same time hyperspectral radiance sensor technology is becoming increasingly affordable. Techniques that include the application of reflectance measurements above the water surface from stationary and moving platforms alike are expected to gain more wide spread usage. As enormous amounts of data are produced and favorably processed in real-time, effective quality control procedures become more than just supporting tools, but a crucial prerequisite for trustworthy and manageable information.

In calibrated above-water radiometry, remote sensing reflectance $R_{R S}(\theta, \varphi, \lambda)$ or water leaving radiance $L_{W}(\theta, \varphi, \lambda)$, can be derived from mobile or fixed platform irradiance and radiance measurements. To derive $L_{W}$ we directly measure sky leaving radiance $L_{S k y}\left(\theta_{S k y}, \varphi, \lambda\right)$ and total upwelling sea surface radiance $L_{T}\left(\theta_{T}, \varphi, \lambda\right)$. The main challenge with $L_{T}$ measurements is that they are affected by meteorological conditions and surface reflectance $L_{S R}$ contamination [1]-[4]. The main components of this surface reflectance are the speculary reflected skylight (sky glint), speculary reflected sunlight (sun glint), whitecaps and foam $L_{W F}$. Sky glint $L_{S k y G}$ is usually less than $5 \%$ of the measure $L_{S k y}$ [5]. Sun glint $L_{S G}$ occurs when sunlight is reflected from the sea surface straight into the sea viewing optical sensor field of view. A wind roughened sea surface will have enhanced sun glint as more reflecting facets are created at the sea surface. It therefore depends on sensor geometry, sun position, cloud cover, and wind speed [4]-[7]. Investigations of $L_{W F}$ suggest it can causes a decrease in reflectance as under water cloud air bubbles that are far apart enough increase water absorption in the NIR [8, 9], or physical coolness of residual foam [10]. In another study it is assumed to enhance reflectance occurring as soon as waves break generating thick strong reflecting foam [11]. Therefore, $L_{S R}$ can be quantified as

$$
L_{S R}=L_{W F}+L_{S k y G}+L_{S G}
$$

At low altitudes where atmospheric path radiance is negligible $L_{W}$ is the difference between $L_{T}$ and $L_{S R}(\theta, \varphi, \lambda)$ from Eq. (1) giving

$$
L_{W}=L_{T}-L_{S R}
$$

Since determining all the components of Eq. (1) is still a challenge, mainly because of the dancing facets of glint that behave in a haphazard unknown manner as well as whitecaps and foam contribution effects $[12,13]$, we approximate $L_{W}$, by simplifying Eq. (2) according to Morel [1]

$$
L_{W}=L_{T}-L_{S k y G}=L_{T}-\left(\rho_{a i r-s e a} \cdot L_{S k y}\right)
$$

where $\rho_{\text {air-sea }}$ is the sky glint correction coefficient at the airsea interface [14]. The nadir and zenith plane angles of the optical sensors are $\theta_{T}=\theta_{S k y}$ with typical angle range $(30-$ $50)^{\circ}$ whilst the relative azimuth angle of the sensors to the sun $\varphi$ range $(90-135)^{\circ}$. Hence, to compute $R_{R S}$ divide $L_{W}$ in Eq. (3) by total downwelling irradiance $E_{D}(\lambda)$.

In this study we assess different approaches for calibrated above-water measurements aimed at mitigating specular surface reflection or surface reflected glint. We also appraise steps taken in collecting radiometric quantities and estimating $L_{W}$ 


\begin{tabular}{|l|l|l|}
\hline $\begin{array}{l}\text { Optical sensor zenith } \\
\text { angle, } \theta_{T} \text { and } \theta_{S k y}\left[^{\circ} \text { ] }\right.\end{array}$ & $\begin{array}{l}\text { Relative azimuth angle } \\
\text { of sensor to the sun, } \varphi\left[^{\circ}{ }^{\circ}\right.\end{array}$ & Report \\
\hline 135,45 & $>90$ or 135 & Fougnie et al. [13], Deschamps et al. [17] \\
\hline 135,45 & 90 & Toole et al. [18] \\
\hline 140,40 & 135 & Mobley [14], Hooker et al. [19], Ruddick et al. [15] \\
\hline $150-130,30-50$ & $90-180$ & Mueller et al. [2] \\
\hline 150,30 & 90 & Gould et al. [20], Lee et al. [12] \\
\hline 135,45 & $0-360$ & Garaba et al. [3] \\
\hline 140,40 & $30-180$ & Harmel et al. [16] \\
\hline
\end{tabular}

TABLE 1 Typical sensor geometry applied in above-water remote sensing.

and $R_{R S}$. Field observations are then used to test different surface reflected glint correction approaches.

\section{CHALLENGES IN ABOVE WATER RADIOMETRY}

There are several factors influencing the accuracy and precision of optical sensing above the sea surface, which will be discussed below. Additionally, high accuracy and precision commands excellent sensor sensitivity and calibration, platform stability and a thorough understanding of all in water properties and surface process influencing light $[2,15,16]$. We present some of the major sources of error affecting the estimation of remote sensing/radiance reflectance $R_{R S}$.

\subsection{Sensor geometry}

To-date acceptable geometry for above-water radiometry is still subjective. Table 1 shows how the viewing angles vary from different studies. In case of automated and unmanned shipborne observations the relative azimuthal angle of the sensor to the sun is variable.

The main goal of having the optical sensors $(90 \leq \varphi \leq 135)^{\circ}$ and $\left(30 \leq \theta_{S k y} \leq 50\right)^{\circ}$ is to limit the problems of sun glint, ship shadow and ship reflection $[2,13,14]$. Garaba et al. [3, 21] propose using a camera system to obtain sea and sky facing images. Using the sea surface images as sea-truth it is shown, with caveats, that at a high enough distance above seawater (12 $\mathrm{m}$ in their case) valid measurements can be obtained at $(0<\varphi \leq 360)^{\circ}$ with little ship shadow effect. These measurements were mostly under overcast skies hence little shadow effect. Harmel et al. [16], do also obtain measurements for at $(30<\varphi \leq 180)^{\circ}$ although they recommend $\varphi=90^{\circ}$. Ship antennas, size, and useable area for sensor setup can be limited, which could make it a challenge to maintain the suggested geometry even-though it is widely applied. Additionally roll and pitch motions of the ship do also affect above-water sensor geometry.

\subsection{Environmental changes}

Wave action is a problem for above water optical sensing as it influences glint and dynamic changes of IOPs and AOPs $[22,23]$. The sea surface is roughened with increase in wind speed, enhanced wave focusing by capillary waves in the near surface waters and hence more sun glint is expected given that we have a non-overcast sky. Wave action also influences sea spray which could affect optical sensors as well as foam and whitecaps which again influence the signal reaching a sensor [3]. It also follows that cloud cover plays a role by influencing further sky glint contribution to measurable radiation. In case of scattered clouds it is a challenge to perform accurate reflectance sensing $[2,14,18]$. Ideal environmental conditions would be little to no wave action, clear or fully overcast sky, and low solar zenith angles. Thus, non-ideal conditions are prone to higher errors as wave action and glint effect correction would have to be very accurate. Moore [5] emphasizes that at low solar zenith angles $\left(<50^{\circ},<80^{\circ}\right)$ there is little sun glint $(<13 \%,<35 \%)$ based on theoretical Smithsonian meteorological tables.

\subsection{Sensitivity and calibration of instruments}

Environmental parameters especially wind speed, absorption, backscattering, radiance and irradiance can be accurately determined using commercially available instruments [24]. Such parameters are valuable in simulations of ocean dynamics and modeling. To better approximate $R_{R S}$ these parameters have to be observed with high accuracy and precision. With time and usage instruments demand routine calibration and sometimes their sensitivity or detection capabilities become depleted due to lifespan of sensors, superstructure perturbations, or improper use $[15,25,26]$.

\section{SURFACE GLINT CORRECTION APPROACHES}

The approaches that will be considered in this study are; Mobley [14], Gould et al. [20], Ruddick et al. [15], Lee et al. [12] and Garaba et al. [3]. Henceforth referenced as M99, G01, R06, L10 and Ga12 respectively. We evaluate these approaches as they are widely used in shipborne above-water radiometry.

\subsection{M99 approach}

Hydrolight (Sequoia Scientific Inc., USA) or www.hydrolight. info a radiative transfer numerical model used to solve the radiative transfer equation for a given set of possible conditions at sea. M99 uses Hydrolight to investigate how sensor setup, meteorological conditions and wind speeds can influence the estimation of $R_{R S}$. He also shows how these conditions also influence sky glint correction. It is also important to 


\begin{tabular}{|l|l|l|}
\hline Parameter & Effect & Recommendation \\
\hline Cloud cover & $\begin{array}{l}\text { Presence of clouds in sky viewing sensor region increase } \\
\text { sky glint especially cumulus clouds at infrared wave- } \\
\text { lengths. Partly cloudy skys increase } \rho_{\text {air }- \text { sea value but }} \\
\text { not in a predictable way. }\end{array}$ & $\begin{array}{l}\text { For heavy overcast sky } \rho_{\text {air-sea }}=0.028 \\
\text { is sufficient or clear sky enhance } \rho_{\text {air-sea }} \\
\text { correction. }\end{array}$ \\
\hline $\begin{array}{l}\text { Sensor viewing an- } \\
\text { gle }\end{array}$ & $\begin{array}{l}\text { At some azimuthal angles of sensor to sun there is likely } \\
\text { to be ship shadow and sun glint. }\end{array}$ & $\begin{array}{l}\text { Water surface radiance optical sensor at } \\
40^{\circ} \text { from the nadir and } 40^{\circ} \text { from the } \\
\text { zenith for the sky viewing sensor, whilst } \\
\text { facing } 135^{\circ} \text { away from the sun. }\end{array}$ \\
\hline Solar zenith angle & $\begin{array}{l}\text { At lower solar zenith angles and high wind speed more } \\
\text { sun glint reaches the sensor. }\end{array}$ & $\begin{array}{l}\text { Avoid sun glint using the sensor viewing } \\
\text { angles suggested above and for increas- } \\
\text { ing wind speeds, enhance } \rho_{\text {air-sea }} \text { correc- } \\
\text { tion } \sim(0.02-0.12) \text { at lower solar zenith } \\
\text { angles }\left(<40^{\circ}\right) \text { and at higher solar zenith } \\
\text { angles }\left(>40^{\circ}\right)\end{array}$ \\
\hline Wind speed & $\begin{array}{l}\text { High wind speeds roughen the sea surface, more danc- } \\
\text { ing faces of glitter, and multiple scattering reflecting } \\
\text { more light into the optical sensor both from unwanted } \\
\text { parts of the sky and sea surface. }\end{array}$ & $\begin{array}{l}\text { At high wind speeds for clear sky in- } \\
\text { crease } \rho_{\text {air-sea }} \text { but this also depends on } \\
\text { the solar zenith angle and overcast sky } \\
\rho_{\text {air-sea }}=0.028 \text { is sufficient. }\end{array}$ \\
\hline
\end{tabular}

TABLE 2 Hydrolight simulated effects of parameters affecting above water remote sensing.

note that a similar investigation also looked at how sensor geometry and cloud cover influenced reflectance computations [1]. These simulations did not look at how $\rho_{\text {air-sea }}$ is dependent on wavelength. Table 2 gives a summary of the scenarios examined using Hydrolight and the results.

After a number of simulations from Hydrolight, M99 suggests a sensor setup where the sensor views the water surface at $40^{\circ}$ from the nadir and $40^{\circ}$ from the zenith for the sky viewing sensor, whilst facing $135^{\circ}$ away from the sun. In this sensor setup it is assumed that there will be minimal sun glint. To remove surface reflected glint it is recommended $\rho_{\text {air-sea }}=0.028$ for clear skies and wind speed less than $5 \mathrm{~m} / \mathrm{s}$, or higher wind speeds a higher $\rho_{\text {air-sea }}$ is necessary. For cloudy skies at all wind speeds he recommends $\rho_{\text {air-sea }}=0.028$ using Eq. (4),

$$
R_{R S}=\frac{L_{W}}{E_{D}}=\frac{L_{T}-\left(\rho_{\text {air-sea }} \cdot L_{S k y}\right)}{E_{D}}
$$

In his investigations he clearly shows that cloud cover haunts all forms of above-water radiometry. With caveats, he suggests residual sun glint correction using the value of $R_{R S}(\lambda=750) \mathrm{nm}$. The surface reflected glint correction with this residual component is likely to have uncertainties in strong scattering waters. If non-optimum viewing geometry is used, a table of $\rho_{\text {air-sea }}$ values as a function of wind speed, solar zenith angle, and viewing direction can be downloaded from http://www.oceanopticsbook.info/view/remote_sensing/ level_3/surface_reflectance_factors.

\subsection{Gorapproach}

The spectral properties of seawater in the near-infrared (NIR) wavelength range can be used in glint correction. Beyond $700 \mathrm{~nm}$ there is a rapid decline in $R_{R S}$ which is a result of enhanced absorption by pure water. In addition, absorption by phytoplankton and colored dissolved organic matter
(CDOM) are negligible at NIR wavelengths, and the spectral absorption curves for these components are essentially flat over the narrow spectral range from $(715-735) \mathrm{nm}$. Thus, water reflectance in this spectral region is tightly coupled to the backscattering coefficient. According to G01, surface glint reflectance $R_{S R}$ consists of a spectrally-variable sky radiance component $\left(\rho_{\text {air-sea }} \cdot R_{\text {sky }}\right)$, and a spectrally-constant sun glint and sky glint component $(B)$,

$$
R_{S R}=\rho_{\text {air-sea }} \cdot R_{\text {sky }}+B
$$

Thus, to estimate and correct for the surface reflectance contribution $\left(R_{S R}\right)$, estimates of $\rho$ and $B$ are essential. G01 is twopath correction approach. If no in situ absorption and scattering measurements are available, the G01 Path 1 uses $\rho_{\text {air-sea }}$ set to Fresnel reflectance $=0.021$. To derive $B, R_{S R}$ is first estimated at $735 \mathrm{~nm}$,

$$
\begin{aligned}
& R_{S R}(\lambda=735) \\
= & \frac{\frac{L_{T}(\lambda=735)}{E_{D}(\lambda=735)} * a_{W}(\lambda=735)-\frac{L_{T}(\lambda=715)}{E_{D}(\lambda=715)} * a_{W}(\lambda=715)}{a_{W}(\lambda=735)-a_{W}(\lambda=715)}
\end{aligned}
$$

where $L_{T} / E_{D}$ is the measured, total, above-water reflectance (including both water and surface-reflected terms), and $a_{w}$ is the absorption of pure water at the given wavelength i.e. $a_{w}(\lambda=715)=1.007 \mathrm{~m}^{-1}$ and $a_{w}(\lambda=735)=2.250 \mathrm{~m}^{-1}$ $[27,28]$. The assumptions here are that the surface reflectance and backscattering coefficient are nearly flat between (715 - 735) nm. See Gould et al. [20] for the derivation of Eq. (6). Finally, the offset component Bis derived from Eq. (5) as

$$
B=R_{S R}(735)-\rho \cdot \frac{L_{S k y}(735)}{E_{D}(735)}
$$

The offset $B$ is expected to include any errors resulting from the above assumptions. Thus $R_{R S}$ is corrected for surface reflected glint with Eq. (8),

$$
R_{R S}=\frac{L_{W}}{E_{D}}=\frac{L_{T}-\left(\rho_{\text {air-sea }} \cdot L_{S k y}\right)}{E_{D}}-B
$$


The alternative correction approach G01 Path 2 requires in situ measurements of inherent optical properties. Using the available measured inherent optical properties, $R_{S R}$ is calculated at two wavelengths $412 \mathrm{~nm}$ and $735 \mathrm{~nm}$, then, with measured $R_{S k y}$ new $\rho$ and $B$ terms are calculated (i.e., $\rho_{\text {air-sea }}$ is no longer assumed to be $=0.021$ ). This Path 2 approach provides a better correction, because the estimates of the $\rho_{\text {air-sea }}$ and $B$ coefficients are constrained using $R_{S R}$ estimates at two wavelengths. However, it depends on accurate in situ optical measurements (which are collected fairly routinely now with ac-9 instruments, for example). See Gould et al. [20] for the complete Path 2 description. G01 Path 1 and Path 2 approaches were tested and assumed to work best in turbid coastal waters where there is a significant $R_{S R}$ signal measured in the (715 - 735) nm wavelength range.

\subsection{Ro6 approach}

Using simulations [14, 29] and field measurements R06 surface reflected glint correction has a dynamic $\rho_{\text {air-sea }}$ which is a function of wind speed and cloud cover. Measurements during overcast skies are corrected for surface reflected glint with $\rho_{\text {air-sea }}=0.0256$, but for clear to partly cloudy conditions $\rho_{\text {air-sea }}$ has a wind speed dependence that can change by up to a factor of two. R06 is appropriate for turbid (total suspended matter $\sim 0.3 \mathrm{~g} / \mathrm{m}^{3}$ ) to very turbid waters (total suspended matter $\sim 200 \mathrm{~g} / \mathrm{m}^{3}$ ). In fact, with increase in turbidity it is estimated that sky glint removal errors are less significant in relative terms with regards to marine reflectance. Cloud cover presence is modeled using $L_{S k y}$ and $E_{D}$ at $(\lambda=735 \mathrm{~nm})$. However, intermediate conditions are still to be investigated therefore it is recommended to eliminate them when using this approach. Eq. (9) and Eq. (10) are used to determine which $\rho_{\text {air-sea }}$ is appropriate for sky glint correction,

$$
\frac{L_{S k y}(\lambda=750)}{E_{D}(\lambda=750)} \geq 0.05 \rightarrow \rho_{\text {air-sea }}=0.0256
$$

or

$$
\begin{aligned}
\frac{L_{S k y}(\lambda=750)}{E_{D}(\lambda=750)} & <0.05 \rightarrow \rho_{\text {air-sea }} \\
& =0.0256+0.00039 W+0.000034 W^{2}
\end{aligned}
$$

where $W$ is the wind speed. The appropriate $\rho_{\text {air }- \text { sea }}$ from Eq. (9) or Eq. (10) is used in Eq. (4) to compute $R_{R S}$ corrected for surface reflected glint. The simulations in this R06 approach are based on M99 with the addition of a cloud presence prediction model. Additionally, it is recommended to set $\Phi=135^{\circ}$ for minimal sun glint. A residual sun glint or white offset correction $\varepsilon=\left[\alpha^{*} R_{R S}(\lambda=780)-R_{R S}(\lambda=720)\right] / \alpha-1$ can be implemented as in a previous study with $\alpha=2.35$ [30].

\subsection{L10 approach}

The spectral optimization aims to remove surface reflected radiance and in-water contributions to the reflected signal. It also shows how $\rho_{\text {air-sea }}$ changes for each measurement and wavelength. The first step involves calculation of raw reflectance here termed first guess reflectance $R_{\text {guess }}$ which is computed according to Eq. (11),

$$
R_{\text {guess }}=R_{\text {Fres }}-R_{\text {mean }} \_ \text {NIR }
$$

where $R_{\text {Fres }}$ is the radiance reflectance calculated using $\rho_{\text {air-sea }}=0.022$ and $R_{\text {mean_NIR }}$ is the mean $R_{\text {Fres }}$ between (750 - 800) nm which can be assumed to be the spectrally constant offset. The next step involves using a hyperspectral bio-optical model - HOPE [31, 32] to solve the inverse problem of modeling absorption and scattering from $R_{\text {Fres }}$ and $R_{\text {guess }}$. It calculates the (i) total absorption coefficients i.e. absorption coefficient of phytoplankton pigments, of pure water, and of Gelbstoff or CDOM and detritus, (ii) backscattering coefficients i.e. backscattering coefficient of suspended particles and seawater, (iii) spectral power for particle backscattering coefficient, and (iv) ratio of backscattering coefficient to the sum of absorption and backscattering coefficients. These parameters derived from HOPE are used to determine radiance reflectance just below the seawater surface $R_{\text {below }}$ and using Eq. (12) to derive a modeled above-water reflectance $R_{\text {above }}[33,34]$

$$
R_{\text {above }}=\frac{0.52 * R_{\text {below }}}{1-\left(1.7 * R_{\text {below }}\right)}
$$

Therefore to compute the bias delta $(\Delta)$ also known as the surface reflection correction value an objective function Eq. (13) that uses $R_{\text {above }}$ and $R_{\text {guess }}$ is implemented

$$
\begin{aligned}
& \text { Err } \\
& =\left[\bigcup_{400}^{675}\left(R_{\text {guess }}-R_{\text {above }}\right)^{2}+\bigcup_{750}^{800}\left(R_{\text {guess }}-R_{\text {above }}\right)^{2}\right]^{0.5} \\
& \bigcup_{400}^{675} R_{\text {guess }}+\bigcup_{750}^{800} R_{\text {Fres }}
\end{aligned}
$$

where $R_{\text {guesss }}$ is from Eq. (11), $R_{\text {above }}$ is modeled radiance reflectance from Eq. (12), $\bigcup_{400}^{675}$ is the mean radiance reflectance $(400-675) \mathrm{nm}$ as explained in L10. The upper limit can be increased if measurements beyond $800 \mathrm{~nm}$ are available. Initially $\Delta=R_{\text {mean_NIR }}$ and by adjusting it until Err is minimal would be the optimization procedure. The optimized reflectance $R_{o p t}$ is then computed, with the $\Delta$ resulting in a very small Err, as in Eq. (14),

$$
R_{o p t}=R_{\text {Fres }}-\Delta=\frac{L_{t}-\left(\rho_{\text {air-sea }} \cdot L_{s k y}\right)}{E_{d}}-\Delta
$$

Therefore the task here is to minimize the difference between $R_{\text {above }}$ and $R_{\text {opt }}$. The result of Eq. (14) $R_{o p t}$ is the reflectance corrected for surface reflected glint.

\subsection{Ga12 approach}

This approach integrates the M99, G01, R06 and L10 approaches with a new automated sun glint image detection algorithm. The sensor setup takes advantage of a dual dome camera system (Mobotix AG, Germany) which makes it possible to obtain sky and sea surface images synchronized with the hyperspectral radiometer observations. Both the camera and radiometer systems are positioned is such a way that their field of view and target area matches for comparison purposes.

Quality control as proposed in this method involves several steps; meteorological flagging [35] on downwelling irradiance $E_{D}$ measurements i. $E_{D}(\lambda=480 \mathrm{~nm})>20 \mathrm{~mW} \cdot \mathrm{m}^{-2} \cdot \mathrm{nm}^{-1}$ setting a threshold for which significant $E_{D}$ can be measured, 


\begin{tabular}{|l|l|l|}
\hline Approach & Benefits & Drawbacks \\
\hline M99 & $\begin{array}{l}\text {-sky glint correction also accounts for wind } \\
\text { speed for clear skies } \\
\text {-useful in different water bodies and cloud con- } \\
\text { ditions based on Hydrolight simulations }\end{array}$ & $\begin{array}{l}\text {-based on numerous Hydrolight simulations with } \\
\text { limited field data } \\
\text {-uses a constant } \rho_{\text {air-sea }} \text { for wind speeds }<5 \mathrm{~m} / \mathrm{s} \\
\text {-suggests use of Black Pixel Assumption [38] for } \\
\text { residual sun glint correction or white offset }\end{array}$ \\
\hline G01 & $\begin{array}{l}\text {-allows use of IOPs in glint correction (Path 2) } \\
\text {-useful in coastal waters } \\
\text {-was tested under a wide range of cloud cover } \\
\text { and water types }\end{array}$ & $\begin{array}{l}\text { form well } \\
\text {-Path 1 uses a constant } \rho_{\text {air-sea }}\end{array}$ \\
\hline R06 & $\begin{array}{l}\text {-useful in turbid to very turbid waters } \\
\text { - } \rho_{\text {air-sea }} \text { coefficient is a function of wind speed } \\
\text { and cloud cover }\end{array}$ & $\begin{array}{l}\text {-uses a constant } \rho_{\text {air-sea }} \\
\text {-assumes the similarity spectrum } \\
\text {-white offset correction depends on water body and a } \\
\text { challenge in highly turbid waters [30] }\end{array}$ \\
\hline L10 & $\begin{array}{l}\text {-corrects for both sun and sky glint } \\
\text {-useful in clear to turbid waters }\end{array}$ & $\begin{array}{l}\text {-uses a constant } \rho_{\text {air-sea }} \\
\text {-optimizes the spectra using inverse hyperspectral } \\
\text { bio-optical modeling }\end{array}$ \\
\hline Ga12 & $\begin{array}{l}\text {-it use sea surface images to detect excess glitter } \\
\text { in radiometer field of view } \\
\text {-implements all M99, G01, R06 and L10 to ob- } \\
\text { jectively decide on which approach to eliminate } \\
\text { surface reflected glint }\end{array}$ & $\begin{array}{l}\text {-uses thresholds to eliminate glint contamination and } \\
\text { therefore is region specific } \\
\text {-needs a camera system to obtain sea surface images } \\
\text { for the sun glint detection algorithm }\end{array}$ \\
\hline
\end{tabular}

TABLE 3 An evaluation of the surface reflected glint correction approaches.

ii. $E_{D}(\lambda=470 \mathrm{~nm}) / E_{D}(\lambda=680 \mathrm{~nm})<1$ masking spectra affected by dawn/dusk radiation, iii. $E_{D}(\lambda=940 \mathrm{~nm}) / E_{D}$ $(\lambda=370 \mathrm{~nm})<0.25$ masking spectra affected by rainfall and high humidity. $E_{D}$ spectra that passed this meteorological flagging and corresponding $L_{T}, L_{S k y}$ measurements are used to derive $L_{W}$ and $R_{R S}$ with surface reflected glint corrected according to M99, G01, R06, and L10. The corrected spectra are ranked considering the number of negative valued spectra for each measurement. The image detection algorithm is also used to distinguish between sea surface images having too much or detectable white pixels or sun glint and those having least visible/detectable white pixel or sun glint. Having the two image sets their corresponding spectra ( $L_{W}$ and $R_{R S}$ ) are then evaluated to determine distinctive characteristics e.g. spectral shape. These characteristics therefore make the threshold parameters of eliminating excess surface reflected glint. Ga12 is more appropriate for automated and unmanned observations as it comes with a meteorological flagging algorithm and excessive sun glint image detection algorithm.

\subsection{Evaluation of the approaches}

We look at surface reflected glint correction approaches M99, G01, R06, L10 and an integrated approach which combines all these approaches with an sun glint image detection algorithm [3]. These approaches implement constrained radiative transfer equations e.g. wind speed and cloud cover [15] or inverse hyperspectral bio-optical model - HOPE [31, 32]. In each method there are benefits and drawbacks (Table 3) which are influenced by meteorological, geographic, temporal conditions and seawater constituents.

Although, it is not the scope of this review, there are other methods that can be used in determining remote sensing near the sea surface, minimizing surface reflected glint,

(i) measuring just below the sea surface using the novel hyperspectral skylight-blocked approach - HyperSBA [36]

- this approach of measuring water leaving radiance just below the sea surface and also above-water to determine sea surface glint in optically complex coastal and inland waters was evaluated in a new glint removal method [37]. In this approach, $L_{T} / E_{D}$ or upwelling radiance/irradiance spectra for the intervals $(350-380) \mathrm{nm}$ and $(890-900) \mathrm{nm}$ is used as reference reflectance. A power curve fit is applied to the reference reflectance, so far tested only with the MS Excel (Microsoft, USA) and can give a different result in other software e.g. MALAB (MathWorks Inc., USA) with more power curve fit options. The resultant spectral signal is assumed to be glint

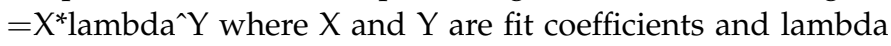
is the wavelength, is then subtracted from observed $L_{T} / E_{D}$ to determine corrected reflectance. Although, this is a simple and robust approach [37], it overcorrects for glint effects(as can be seen in Kutser et al. [37] corrected spectra Figure 3, Figure 4, and Figure 6). Their assumption is that glint follows a power function still needs to be fully investigated.

(ii) in-water light profiling and then extrapolate the measured to the sea surface [19], and

(iii) using polarization methods, or taking into account the contribution of polarization, along with radiative transfer tested correction algorithms [13, 16]. Despite, the variable methods available, there are inevitable uncertainties, as we cannot directly estimate water leaving radiance or remote sensing reflectance. Hence the need to accurately measure the 

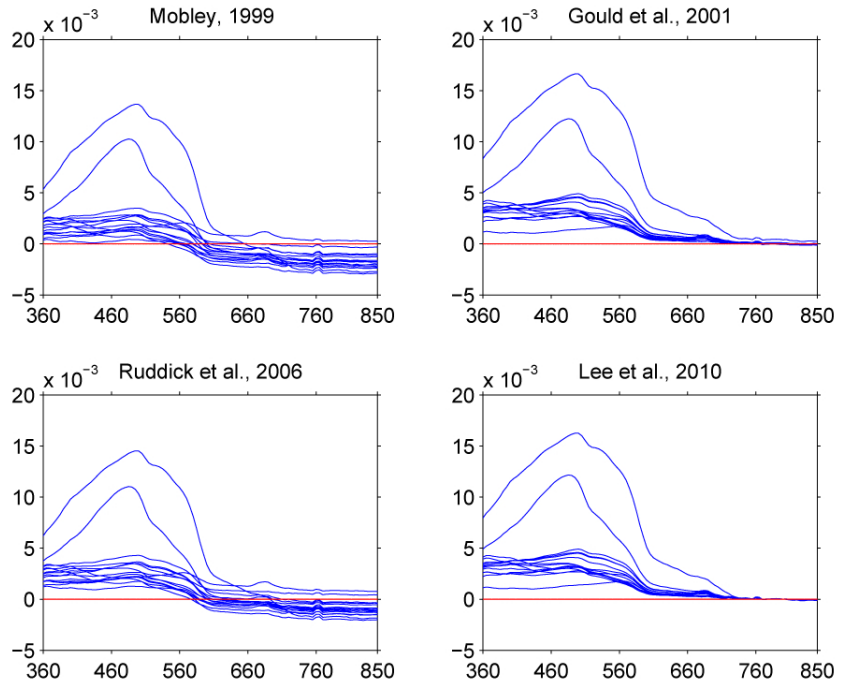

FIG. 1 Reflectance from 15 stations in Case 1 waters with fully overcast skies [39]. The spectra are corrected for glint using different models as shown and the red line indicates the zero $\mathrm{sr}^{-1}$ line.

parameters we can measure directly to reduce sources of error $[18,19,36]$.

\section{CASE STUDIES}

\subsection{Overcast Sky Conditions}

To evaluate these surface glint correction approaches M99, G01, R06 and L10 we use field measurements collected from West Greenland, Labrador Sea, Denmark Strait and West of Iceland [39]. A total of 27 measurements were compared to in-water observations and 15 of these were collected during fully overcast skies. Using the 15 measurements we assume diffuse solar distribution and also that the relative solar to sensor azimuthal dependence of observations is insignificant. Wind speed at all the stations was $<15 \mathrm{~m} / \mathrm{s}$, solar zenith angle ranged $\sim(48-81)^{\circ}$. M99 simulations [14] have shown that under overcast skies and large solar zenith angles the sky reflected glint correction factor is constant.

In this investigation, the M99 and R06 surface reflected glint correction produce negative spectra at longer wavelengths $\lambda>560 \mathrm{~nm}$. The R06 implements $\rho_{\text {air-sea }}=0.0256$ for overcast skies whilst M99 uses $\rho_{\text {air-sea }}=0.028$ for surface reflect glint correction. As illustrated in Figure 1, R06 performs relatively better (less negative spectra) than the M99 and further correction for the white offset or assumed sun glint residual would produce more negative spectra. The G01 corrected spectra did show the best correction with fewer spectra less than zero sr ${ }^{-1}$ compared to all approaches. It was also compared with inwater measurements showing the least unbiased percent differences with respects to M99, R06, and L10. G01 and L10 both implement $\rho_{\text {air-sea }} \sim 0.021$ or Fresnel Reflectance and further correct for residual sun glint or a white offset.

\subsection{Clear Sky Conditions}

Measurements during ideal cloud conditions or clear skies demand effective sun glint correction and have to be ob-
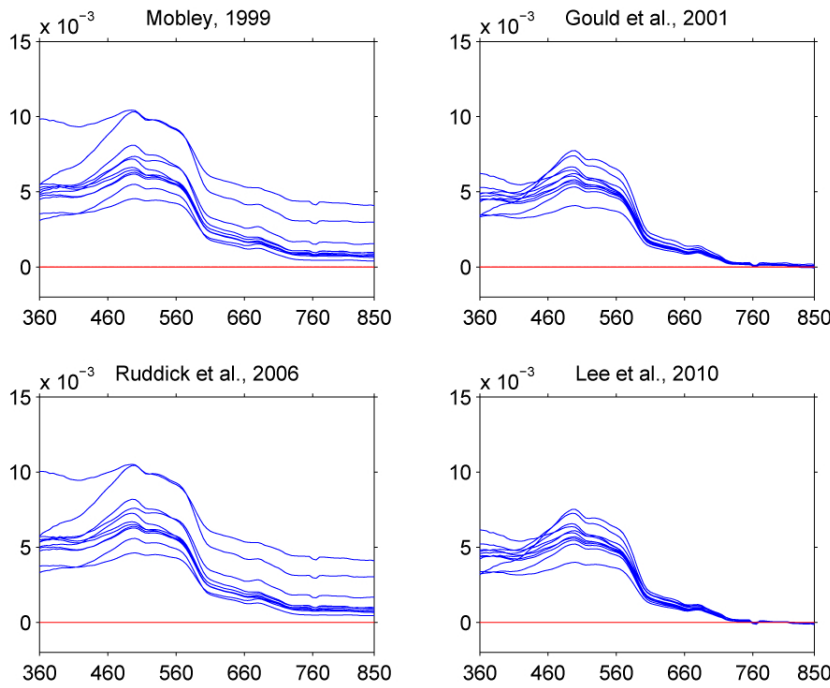

FIG. 2 Reflectance from 11 stations in Case 2 waters with with clear skies [3]. The spectra are corrected for surface reflected glint using different models as shown and the red line indicates the zero $\mathrm{sr}^{-1}$ line.

tained at recommended sensor geometry to avoid excessive glint. Here we present 11 measurements, Figure 2, collected in Case 2 waters of the Northwest European Shelf Seas under clear skies [3]. No in-water measurements were collected during clear sky conditions for this field campaign and therefore surface reflected glint correction is qualitative and semiquantitative as no reference measurement is available. Wind speed at all the stations was $<13 \mathrm{~m} / \mathrm{s}$ and solar zenith angle ranged $\sim(44-69)^{\circ}$ and the relative azimuthal angle of the sensor to the sun was between $(250-288)^{\circ}$. It is possible environmental perturbations e.g. wind speed and sea surface state, and sensor geometry introduce uncertainties in glint correction. However, for this review we assume these errors to be insignificant with regards to our aim of showing how the correction models perform with some caveats.

In this investigation, all correction models M99, G01, R06, and L10 have positive spectra for $\lambda<760 \mathrm{~nm}$. G01 and L10 do have negative spectra beyond $760 \mathrm{~nm}$, they also perform spectra correction in the green, and blue region as their reflectance is lower than M99 and R06. Clear skies require sun glint correction but as shown in Figure 2 the differences seem to be residual glint correction not implanted in M99 and R06 but is this appropriate or necessary? G01 and L10 assume Fresnel reflectance and also residual glint and their respective reflectance in the deep NIR are close or equal to zero. The question here is this possible in shelf seas or coastal waters with highly scattering optically active material? These are some of the question yet to be fully investigated with respect to surface glint correction. R06 $\rho_{\text {air-sea }}$ factor becomes wind depend during clear skies but will this be enough to correct for surface reflected glint?

\section{CONCLUSIONS AND OUTLOOK}

The remaining question after looking at surface reflected glint correction approaches widely implemented in calibrated above-water radiometry is which approach is best? In ac- 
tual fact absolute removal of surface reflected glint is difficult $[14,19,36]$, as evaluated in Table 3. Furthermore, no glint correction approach has been unequivocally brought forward and thus to date surface reflected glint correction depends on the researcher [19]. In addition, taking into account the different geometry setups that have been widely used (Table 1), sea and meteorological conditions are beyond human control. The best ocean color studies can do is estimate water leaving radiance or reflectance with some degree of uncertainties [36]. The literature we look at in this report does not cover all available approaches but rather we provide a general list of widely used approaches and we are bound to have skipped some important literature. Our aim is to provide the reader with a set of tools on how to perform shipborne above-water radiometry and correct for surface reflected glint effects. Using two case studies we illustrate how each correction approach will perform and the main difference is in the residual glint correction. M99 and R06 do have suggestion on how to do this but very few studies have implemented it whilst in G01 and L10 this correction is applied during surface glint correction. There is little known about all the components of Eq. (1). Therefore in the ocean color community no surface glint correction is assumed to be best and to our knowledge no study has quantitatively compared these methods as also explained by Hooker et al., [19].

A key task in remote sensing is to take stock of sources of uncertainties. However, the question of articulating uncertainties is complicated due to a number of factors, but not exclusively, (i) Sensor stability and calibration methods as more variable commercial radiometers are available [24]. A calibration and sensor stability uncertainty from each vendor and the instrument overtime is therefore likely to exist, (ii) Environmental perturbations - changes in weather, sea surface state and local optically active seawater properties introduce some uncertainties $[19,40]$, overcast skies present another problem as diffuse solar distribution means light is from all directions not focused as when we have clear skies, (iii) Data processing - as shown above there are several glint correction methods and bandwidth binning can introduce some errors $[19,26]$.

Mueller et al. [2] recommend recording ancillary measurements: wind speed, cloud cover, ship heading, ship GPS data, and sea surface and sky images, inherent optical properties where possible. Using the collected sea surface images a sun glint detection algorithm can be implemented to eliminate images highly contaminated with glint [3]. For automated measurement, determine the relative azimuthal angle of the sensor to the sun using e.g. Solar Position Algorithm [41]. Using the ship's position the SPA is useful in computing the sun's azimuthal and zenith angles at a given space-time spot. Extract spectra collected in the optimal relative azimuthal angle of sensor to sun $(90 \leq \varphi \leq 135)^{\circ}$. It is also vital to avoid zenith angles near the horizon as they are problematic due to the Cox-Munk representation often implemented into radiative transfer models e.g. in Hydrolight. There is also waveshadowing effect which is hardly accounted for in these models and could also attribute to increasing uncertainties as we measure at larger zenith angles. The dynamic change in waves at stations makes it important to measure spectra at short intervals e.g. $10 \mathrm{~s}$ depending on sensor $[2,19,25]$.
Assuming that no in-water measurements, to allow inter comparisons, are available and above-water measurements are collected as recommended in ocean color protocols. The best way to evaluate and correct for surface reflected glint would be to apply all the methods and assess the corrected spectra performance in determining ocean color products using insitu data to verify their sensitivity. To test applicability of a correction approach most studies have used qualitative and semi-quantitative techniques. An example of the qualitative analysis would be e.g. Figure 1 of this review, using visual inspection we would eliminate M99 and R06 corrected spectra and the semi-quantitative part would be determining the number of negative spectra or flagging measurements based on solar zenith angle, wind speed or comparing the derived ocean color products from bio-optical modeling for instance Chlorophyll-a. Will this guarantee correct or true measurements? Definitely not but such a process can be tedious and it improves the data quality relatively. Alternatively, observations at sea can be collected at a fixed zenith and azimuthal angles with the radiometer setup also constant although this procedure does however limit the number of measurements. Classifying the models also according to best-fit water bodies will be prone to ambiguity e.g. how to distinguish clear or turbid waters. There is still need to investigate how best to implement glint correction. In this report we advocate for a uniform set of approaches in above-water radiometry for future inter-comparison of in-water and above-water techniques.

\section{ACKNOWLEDGEMENTS}

We thank Heidi Dierssen, Richard Gould, Zhongping Lee, Martin Hieronymi, Curtis Mobley, Kevin Ruddick, Kenneth Voss, and Guiseppe Zibordi for their feedback on this manuscript. Comments and suggestion by two anonymous reviewers is greatly appreciated.

\section{References}

[1] A. Morel, "In-water and remote measurements of ocean color," Bound.-Layer Meteorol. 18, 177-201 (1980).

[2] J. L. Mueller, C. Davis, R. Arnone, R. Frouin, K. Carder, Z. P. Lee, R. G. Steward, et al., Above-Water Radiance and Remote Sensing Reflectance Measurement and Analysis Protocols (Coddard Space Flight Space Center, Greenbelt, 2003).

[3] S. P. Garaba, J. Schulz, M. R. Wernand, and 0. Zielinski, "Sunglint detection for unmanned and automated platforms," Sensors 12, 12545-12561 (2012).

[4] S. Kay, J. Hedley, and S. Lavender, "Sun Glint Correction of High and Low Spatial Resolution Images of Aquatic Scenes: a Review of Methods for Visible and Near-Infrared Wavelengths," Remote Sens. 1, 697-730 (2009).

[5] G. K. Moore, "Satellite remote sensing of water turbidity / Sonde de télémesure par satellite de la turbidité de l'eau," Hydrolog. Sci. J. 25, 407-421 (1980).

[6] H. Zhang and M. Wang, "Evaluation of sun glint models using MODIS measurements," J. Quant. Spectrosc. Ra. 111, 492-506 (2010).

[7] J. S. Barton, and M. F. Jasinski, "Sensitivity of depth-integrated 
satellite lidar to subaqueous scattering," Remote Sens. 3, 1492-1515 (2011).

[8] C. H. Whitlock, D. S. Bartlett, and E. A. Gurganus, "Sea foam reflectance and influence on optimum wavelength for remote sensing of ocean aerosols," Ceophys. Res. Lett. 9, 719-722 (1982).

[9] R. Frouin, M. Schwindling, and P.-Y. Deschamps, "Spectral reflectance of sea foam in the visible and near-infrared: In situ measurements and remote sensing implications," J. Geophys. Res. 101, 14361-14371 (1996).

[10] G. 0. Marmorino, and G. B. Smith, "Bright and dark ocean whitecaps observed in the infrared," Ceophys. Res. Lett. 32, L11604 (2005).

[11] K. D. Moore, K. J. Voss, and H. R. Cordon, "Spectral reflectance of whitecaps: Instrumentation, calibration, and performance in coastal Waters," J. Atmos. Ocean. Technol. 15, 496-509 (1998).

[12] Z. Lee, Y.-H. Ahn, C. Mobley, and R. Arnone, "Removal of surfacereflected light for the measurement of remote-sensing reflectance from an above-surface platform," Opt. Express 18, 26313-26324 (2010).

[13] B. Fougnie, R. Frouin, P. Lecomte, and P.-Y. Deschamps, "Reduction of skylight reflection effects in the above-water measurement of diffuse marine reflectance," Appl. 0pt. 38, 3844-3856 (1999).

[14] C. D. Mobley, "Estimation of the remote-sensing reflectance from above-surface measurements," Appl. Opt. 38, 7442-7455 (1999).

[15] K. G. Ruddick, V. De Cauwer, Y. J. Park, and G. Moore, "Seaborne measurements of near infrared water-leaving reflectance: The similarity spectrum for turbid waters," Limnol. Oceanogr. 51, 1167-1179 (2006).

[16] T. Harmel, A. Gilerson, A. Tonizzo, J. Chowdhary, A. Weidemann, R. Arnone, and S. Ahmed, "Polarization impacts on the waterleaving radiance retrieval from above-water radiometric measurements," Appl. 0pt. 51, 8324-8340 (2012).

[17] P.-Y. Deschamps, B. Fougnie, R. Frouin, P. Lecomte, and C. Verwaerde, "SIMBAD: A field radiometer for satellite ocean-color validation," Appl. Opt. 43, 4055-4069 (2004).

[18] D. A. Toole, D. A. Siegel, D. W. Menzies, M. J. Neumann, and R. C. Smith, "Remote-sensing reflectance determinations in the coastal ocean environment: Impact of instrumental characteristics and environmental variability," Appl. Opt. 39, 456-469 (2000).

[19] S. B. Hooker, G. Lazin, G. Zibordi, and S. McLean, "An evaluation of above- and in-water methods for determining water-leaving radiances," J. Atmos. Ocean. Technol. 19, 486-515 (2002).

[20] R. W. Gould, R. A. Arnone, and M. Sydor, "Absorption, scattering, and, remote-sensing reflectance relationships in coastal waters: Testing a new inversion algorithm," J. Coast. Res. 17, 328-341 (2001).

[21] S. P. Garaba, M. R. Wernand, and 0. Zielinski, "Quality control of automated hyperspectral remote sensing measurements from a seaborne platform," Ocean Sci. Discuss. 8, 613-638 (2011).

[22] G. Zibordi, F. Mélin, J.-F. Berthon, B. Holben, I. Slutsker, D. Giles, D. D'Alimonte, et al., "AERONET-OC: A network for the validation of ocean color primary products," J. Atmos. Ocean. Technol. 26, 1634-1651 (2009).

[23] M. Hieronymi, "Monte Carlo code for the study of the dynamic light field at the wavy atmosphere-ocean interface," J. Europ. Opt. Soc. Rap. Public. 8, 13039 (2013).

[24] C. Moore, A. Barnard, P. Fietzek, M. R. Lewis, H. M. Sosik, S. White, and 0 . Zielinski, "Optical tools for ocean monitoring and research," Ocean Sci. 5, 661-684 (2009).
[25] G. Zibordi, K. Ruddick, I. Ansko, G. Moore, S. Kratzer, J. Icely, and A. Reinart, "In situ determination of the remote sensing reflectance: an inter-comparison," Ocean Sci. 8, 567-586 (2012).

[26] G. Zibordi, J. F. Berthon, F. Mélin, and D. D'Alimonte, “Cross-site consistent in situ measurements for satellite ocean color applications: The BiOMaP radiometric dataset," Remote Sens. Environ. $115,2104-2115$ (2011).

[27] R. M. Pope and E. S. Fry, "Absorption spectrum (380-700 nm) of pure water. II. Integrating cavity measurements," Appl. 0pt. 36, 8710-8723 (1997).

[28] R. M. Pope, Optical absorption of pure water and sea water using the integrating cavity absorption meter (PhD Thesis, Texas ActM University, 1993).

[29] C. Cox and W. Munk, "Measurement of the roughness of the sea surface from photographs of the sun's glitter," J. Opt. Soc. Am. 44, 838-850 (1954).

[30] A. Hommersom, S. Kratzer, M. Laanen, I. Ansko, M. Ligi, M. Bresciani, C. Giardino, et al., "Intercomparison in the field between the new WISP-3 and other radiometers (TriOS Ramses, ASD FieldSpec, and TACCS)," J. Appl. Remote Sens. 6, 063615-063615 (2012).

[31] Z. Lee, K. L. Carder, and R. A. Arnone, "Deriving inherent optical properties from water color: a multiband quasi-analytical algorithm for optically deep waters," Appl. 0pt. 41, 5755-5772 (2002).

[32] Z. Lee, A. Weidemann, J. Kindle, R. Arnone, K. L. Carder, and C. Davis, "Euphotic zone depth: Its derivation and implication to ocean-color remote sensing," J. Geophys. Res. 112, C03009 (2007).

[33] H. R. Gordon, 0. B. Brown, R. H. Evans, J. W. Brown, R. C. Smith, K. S. Baker, and D. K. Clark, "A semianalytic radiance model of ocean color," J. Geophys. Res. 93, 10909-10924 (1988).

[34] Z. Lee, K. L. Carder, C. D. Mobley, R. G. Steward, and J. S. Patch, "Hyperspectral remote sensing for shallow waters. 2. Deriving bottom depths and water properties by optimization," Appl. Opt. 38, 3831-3843 (1999).

[35] M. R. Wernand, "Guidelines for (ship-borne) auto-monitoring of coastal and ocean colour," in Proceedings of Ocean Optics XVI, 13 (The Oceanography Society, Santa Fe, 2002).

[36] Z. Lee, N. Pahlevan, Y.-H. Ahn, S. Greb, and D. O'Donnell, “Robust approach to directly measuring water-leaving radiance in the field," Appl. Opt. 52, 1693-1701 (2013).

[37] T. Kutser, E. Vahtmäe, B. Paavel, and T. Kauer, "Removing glint effects from field radiometry data measured in optically complex coastal and inland waters," Remote Sens. Environ. 133, 85-89 (2013).

[38] D. A. Siegel, M. Wang, S. Maritorena, and W. Robinson, "Atmospheric Correction of Satellite Ocean Color Imagery: The Black Pixel Assumption," Appl. Opt. 39, 3582-3591 (2000).

[39] S. P. Garaba and 0. Zielinski, "Comparison of remote sensing reflectance from above-water and in-water measurements west of Greenland, Labrador Sea, Denmark Strait, and west of Iceland," Opt. Express 21, 15938-15950 (2013).

[40] P. Kowalczuk, M. J. Durako, W. J. Cooper, D. Wells, and J. J. Souza, "Comparison of radiometric quantities measured in water, above water and derived from seaWiFS imagery in the South Atlantic Bight, North Carolina, USA," Cont. Shelf Res. 26, 2433-2453 (2006).

[41] I. Reda, and A. Andreas, "Solar position algorithm for solar radiation applications," Sol. Energy 76, 577-589 (2004). 